Ohcratoxin producing Aspergillus spp. isolated from tropical soils in Sarawak, Malaysia

\author{
Jaya Seelan Sathiya Seelan ${ }^{1} \&$ Sepiah Muid ${ }^{2}$
}

${ }^{1}$ Institute for Tropical Biology and Conservation, Locked bag 2073, Universiti Malaysia Sabah, 88999, Kota Kinabalu, Sabah, Malaysia

${ }^{2}$ Department of Plant Science and Environmental Ecology, Faculty of Resource Science and Technology, Universiti Malaysia Sarawak, 94300 Kota Samarahan, Sarawak, Malaysia Email: ${ }^{1}$ avinash80us@yahoo.com

Aspergillus spp. has been widely studied for mycotoxin analysis. Mycotoxin is considered one of the chemical groups that causes serious side effects in humans and animals. Although Aspergillus spp. contains bioactive compounds, there is a need to screen for mycotoxin metabolites since mycotoxin is hazardous to human health. Ochratoxin is a mycotoxin with nephrotoxic, nephrocarcinogenic, teratogenic and immunosuppressive properties, and has received growing interest in the scientific community and food committees in the last few years (Battaglia et al. 1996; Abarca et al. 2003). Only species belonging to the genera Aspergillus and Penicillium have been reported as capable of producing ochratoxins. They were initially described by Scott (1965) in Aspergillus ochraceus but have also been found in other species of the section Circumdati: A. alliaceus, A. melleus, A. ostianus, A. petrakii, A. sclerotiorum, A.

Date of publication (online): 26 March 2010

Date of publication (print): 26 March 2010

ISSN 0974-7907 (online) | 0974-7893 (print)

Editor: V.B. Hosagoudar

\section{Manuscript details:}

Ms \# 02247

Received 01 July 2009

Final received 23 November 2009

Finally accepted 09 January 2010

Citation: Seelan, J.S.S. \& S. Muid (2010). Ohcratoxin producing Aspergillus spp. isolated from tropical soils in Sarawak, Malaysia . Journal of Threatened Taxa 2(3): 762-765.

Copyright: $\odot$ Jaya Seelan Sathiya Seelan \& Sepiah Muid2010. Creative Commons Attribution 3.0 Unported License. JoTT allows unrestricted use of this article in any medium for non-profit purposes, reproduction and distribution by providing adequate credit to the authors and the source of publication.

Acknowledgements: The authors would like to thank Universiti Malaysia Sarawak (UNIMAS) for permission granted to present these findings and MOSTI for providing financial support for this project. The author is grateful to Prof. Maren Klich of the United States Agricultural Department (USDA) for confirming the indentification of the Aspergillus species.

\section{OPEN ACCESS | FREE DOWNLOAD (C) (i) (4)}

sulphureus (Hesseltine et al. 1972), A. albertensis, A. auricomus (Varga et al. 1996); as well as in the black aspergilli of section Nigri: $A$. niger var. niger, $A$. carbonarius (Samson et al. 2004). In this study, eighteen species of Aspergillus isolated from different habitats were selected to screen for ochratoxin producing strains.

\section{Material and Methods}

Fungal isolates: Eighteen isolates of Aspergillus species were selected (Table 1) and grown on potato dextrose agar (PDA), Czapek's yeast extract agar (CYA), and Malt extract agar (MEA), incubated for 7 days at $25^{\circ} \mathrm{C}$. The strains were identified based on Raper \& Fennell (1965) and Klich (2002). Colonies were mounted in lactophenol blue and images were taken by using a NIKON digital camera.

Extraction and immunochemical tests by using ELISA kit: Each fungus was cultured in a Czapek's yeast extract broth (CYB) medium for 7 days and incubated at $25^{\circ} \mathrm{C}$, in shaker of $120 \mathrm{rpm}$. Crude fermentation broth was blended thoroughly and centrifuged at 4000rpm for 5 minutes. The supernatant was passed through a filtration membrane $(0.22 \mu \mathrm{m}$, Minipore). Then the homogenized broth was extracted with chloroform. The combined organic extract was evaporated under reduced pressure yielding a crude semi-solid (Wang 2002). Then, the extracts were tested by using enzyme-linked immunosorbent assays (ELISAs) test for positive results. ELISA positives were confirmed by HPLC technique.

OA detection by HPLC: The samples were analysed by using a reverse phase HPLC equipped with a Jasco FP. 920 fluorescence detector (330 nm excitation wavelength, $460 \mathrm{~nm}$ emission wavelength). Chromatographic separations were performed on an analytical column (symmetry waters C18 ODS2, $150 \mathrm{~mm} \times 3.9 \mathrm{~mm}, 5 \mu \mathrm{m}$ ) fitted with a precolumn with the same stationary phase. The mobile phase used was pumped at $1.0 \mathrm{ml} / \mathrm{min}$ and consisted of an isocratic program as follows: acetonitrile/ water/acetic acid (99:99:2, v/v). The injection volume was $20 \mu \mathrm{l}$. Samples were taken as positive for OA presence if they yielded a peak at a retention time similar to the OA standard peak (approximately $4 \mathrm{~min}$ ), with a height five times higher than the baseline noise.

\section{Results and Discussion}

ELISAs test: Altogether, 18 Aspergillus strains were tested for OA production by the immunochemical test. Among these, only two strains of Aspergillus, namely, $A$. carbonarius and $A$. sulphureus produced OA when tested with ELISA. The other sixteen strains of Aspergillus did not produce this toxin (Table 1). In temperate regions, $A$. carbonarius and $A$. sulphureus have been widely 

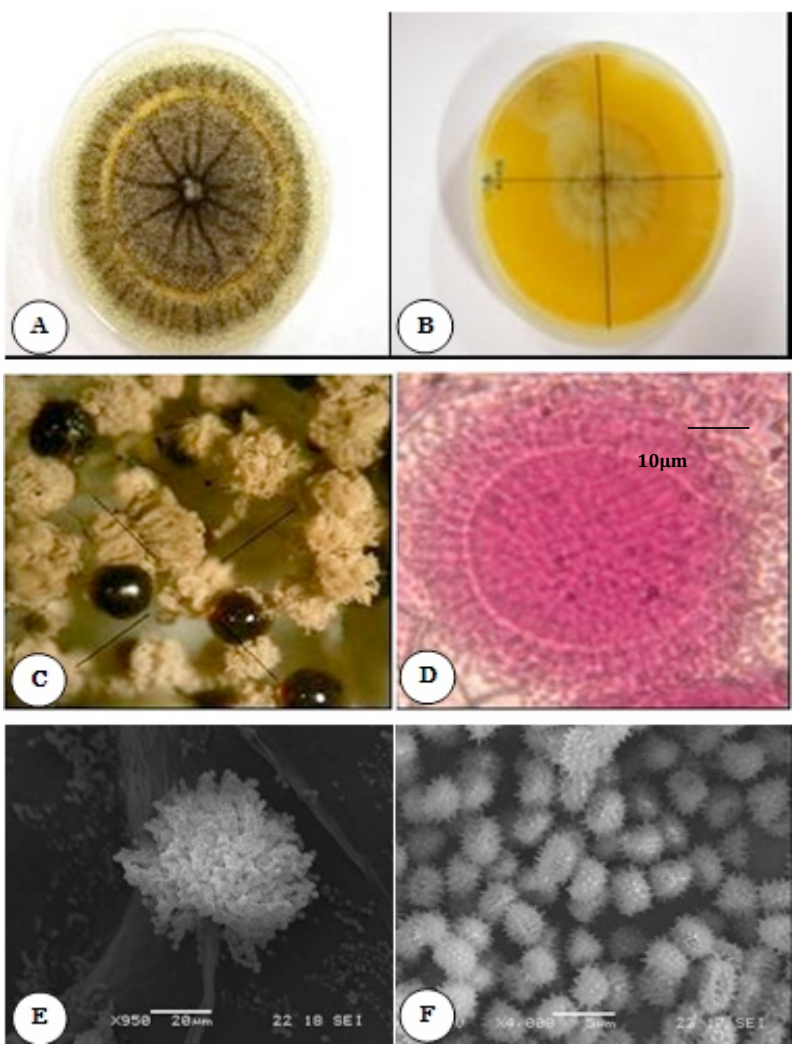

Image 1. Aspergillus carbonarius (JS742).

A - Colony surface on CYA media $\left(7\right.$ days, $\left.25^{\circ} \mathrm{C}\right)$; B - Colony reverse on MEA media ( 7 days, $25^{\circ} \mathrm{C}$ ); $\mathrm{C}$ - Conidial head splitting into diverging columns and producing heavy exudates when mature; D - Conidial head radiate and biseriate; E - SEM of conidial head, $(\mathrm{Bar}=20 \mu \mathrm{m}) ; \mathrm{F}$ - Conidia globose, rough and spikes $($ Bar $=5 \mu \mathrm{m})$.

studied on their OA production. These two species were earlier described as OA producing species (Ciegler 1972; Hesseltine et al. 1972). In this study, we have showed that these tropical strains produce a lower concentration of OA using the czapek's yeast extract broth (CYB). The OA production was influenced by the type of media and the origin of the isolates (Harwig 1974). This was shown when two other $A$. carbonarius were isolated from the peat soil in Bintulu and did not show any OA production under the same liquid media. Thus, not all strains of Aspergillus species are ochratoxin $(\mathrm{OA})$ producers.

\section{Morphological identification of OA producers}

Aspergillus carbonarius (JS742): Colonies on Czapek's yeast extract agar (CYA) $57-58 \mathrm{~mm}$ in diameter ( 7 days, $25^{\circ} \mathrm{C}$ ), wrinkled, dense and velutinous, exudates present, white at first and becomes dark brown with forming of conidial heads, reverse dark yellow. Colonies on malt extract agar (MEA) $52-56 \mathrm{~mm}$ in diameter (7 days, $25^{\circ} \mathrm{C}$ ) similar to those on CYA but less dense and conidia in duller colors, reverse dirty yellow. No growth at $5^{\circ} \mathrm{C}$. Growth at $37^{\circ} \mathrm{C}$ is exceptionally rapid, colonies on CYA 38-40mm in diameter in three days. This strain
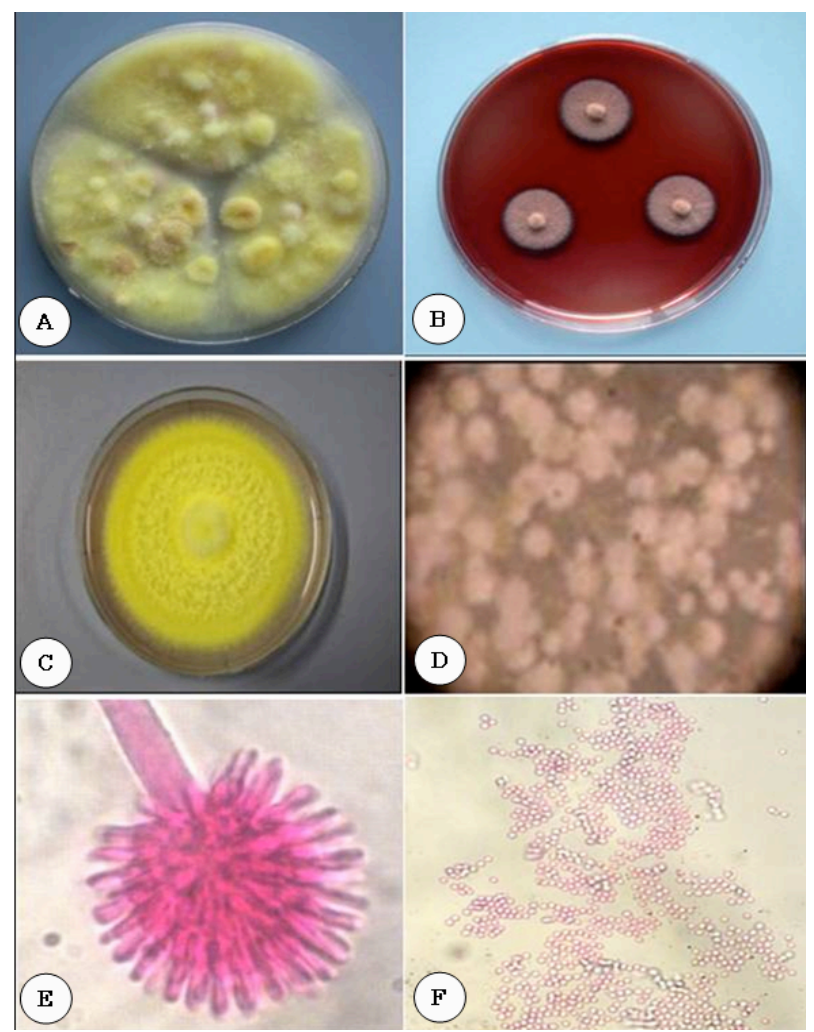

Image 2. Aspergillus sulphureus (JS500).

A - Colony surface on CYA25 media ( 7 days, $\left.25^{\circ} \mathrm{C}\right)$; B - Colony surface on CYA37 media ( 7 days, $37^{\circ} \mathrm{C}$ ); C - Colony surface on $\operatorname{MEA}\left(7\right.$ days, $\left.25^{\circ} \mathrm{C}\right)$; D - Conidial heads white; $\mathrm{E}$ - Uniseriate conidial head $($ Bar $=50 \mu \mathrm{m}) ; \mathrm{F}$ - Conidia $($ Bar $=10 \mu \mathrm{m})$.

can grow at $45^{\circ} \mathrm{C}$. Conidial apparatus develops as erect conidiophores. Tips of conidiophores enlarge and form vesicles with many phialides producing conidia in long chains.

Conidial heads are compactly columnar, 40-48 $\mu \mathrm{m}$ in diameter, dark brown to black. Conidiophores are unbranched, smooth and dark brown, stipes 200-300 x 3-4 $\mu \mathrm{m}$. Vesicles are round to globose shaped, $20-30 \mu \mathrm{m}$ in diameter. Phialides crowded dark brown, 5-7 $\mu \mathrm{m}$ long. Conidia globose to subglobose, roughened, hyaline, and often decidous spinules when young and verruculose at maturity. Sclerotia occasionally produced on CYA (Image 1).

Aspergillus sulphureus (JS500): Colonies on Czapek's yeast extract agar (CYA) 40-50mm in diameter (7 days, $25^{\circ} \mathrm{C}$ ), wrinkled, showing radial furrowing, sulphur yellow in color, forming white conidial heads, reverse pale yellow, presence of abundant sclerotia shading from white to cream to pale yellow. Colonies on malt extract agar (MEA) $60-70 \mathrm{~mm}$ in diameter $\left(7\right.$ days, $\left.25^{\circ} \mathrm{C}\right)$, similar to those on CYA but less dense and conidia dull yellow in color, reverse pale yellow. No growth at $5^{\circ} \mathrm{C}$. Growth at $37^{\circ} \mathrm{C}$ is exceptionally rapid, colonies on CYA $55-60 \mathrm{~mm}$ in diameter in three days. This strain did not grow at $45^{\circ} \mathrm{C}$. Conidial apparatus develops as erect conidiophores. 

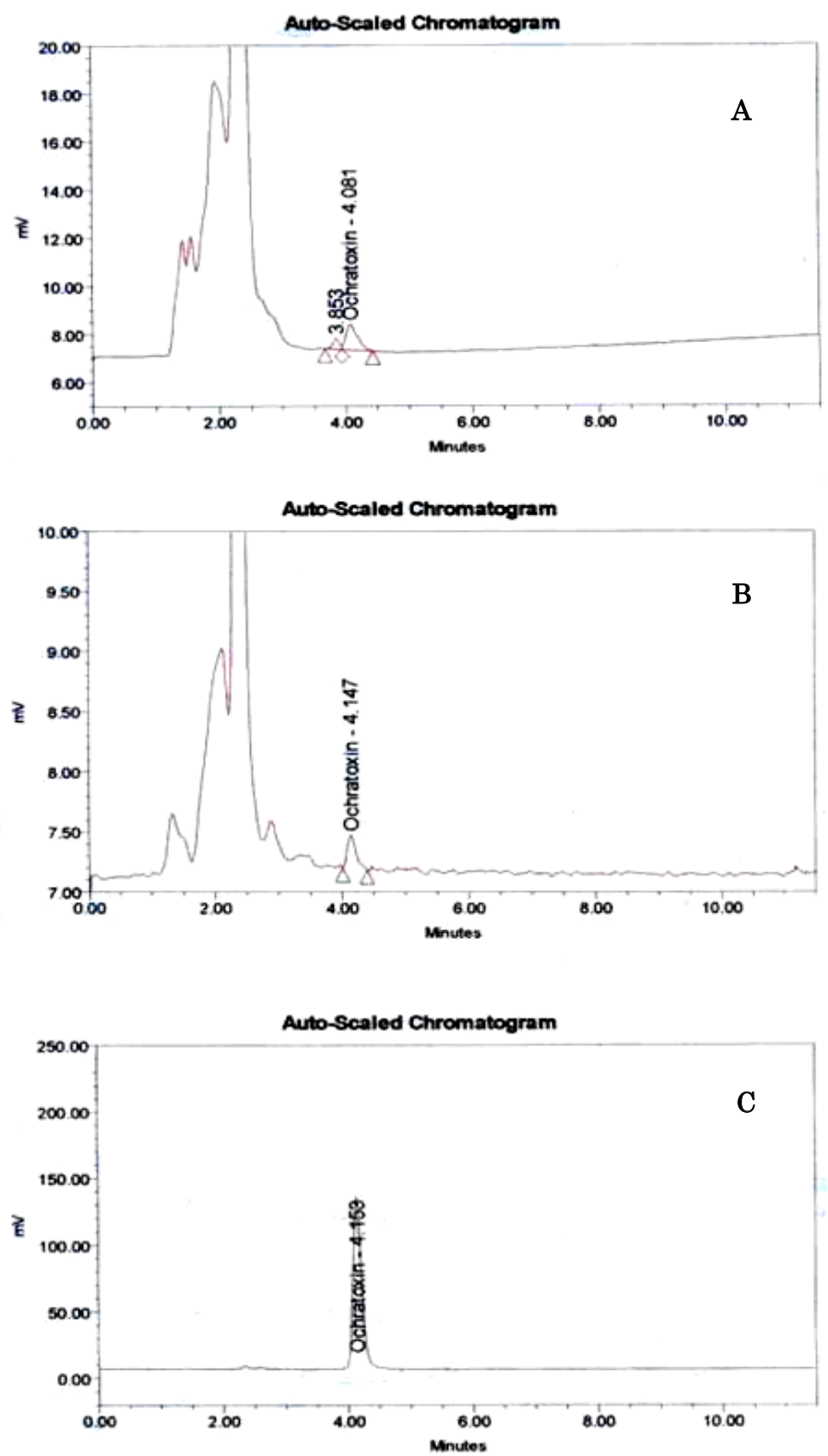

Figure 1. HPLC analyses of crude extracts of

(A) - A. sulphureus (JS500) grown on CYB at the top; (B) - A. carbonarius (742);

(C) - The following metabolite (ochratoxin) produced by this isolate can be identified using retention times and comparing UV spectra from analyses of standard Ohcratoxin A.

Conidial heads are loosely radiate, with spore chains adherent into numerous narrow, divergent and tangled columns, $400-450 \mu \mathrm{m}$ in diameter and white in color. Conidiophores up to $1 \mathrm{~mm}$ long, unbranched, smooth, colorless, stripes 500-650 x 5-7 $\mu \mathrm{m}$. Vesicles hyaline, globose, $12-26 \mu \mathrm{m}$ in diameter. Sterigmata in two series (uniseriate or biseriate). Primaries (uniseriate) 4.5-7.5 x 3.0-4.5 $\mu \mathrm{m}$, secondaries (biseriate) 6.5-8.0 x 2.0-2.5 $\mu \mathrm{m}$. Conidia fusiforms and slightly roughened when first formed, but quickly globose, smooth, 2.0-2.5 $\mu \mathrm{m}$ in diameter (Image 2).

\section{HPLC analyses}

For quantification of OA, an HPLC apparatus equipped with a fluorescent detector was used. Extracts were considered positive if they yielded a peak at a retention time identical to that of standard OA (Figure 1). The amounts of OA observed for $A$. carbonarius and $A$. 
Table 1. List of Aspergillus strains examined for ochratoxin metabolite in this study

\begin{tabular}{|l|l|l|}
\hline Species & $\begin{array}{c}\text { Ochratoxin } \\
\text { content }(\boldsymbol{\mu g} \\
\mathbf{m l}^{-1} \text { ) }\end{array}$ & Strain (sources and origin) \\
\hline A. niveus & ND & JS518 (peat soil, UNIMAS) \\
\hline A. ochraceus & ND & $\begin{array}{l}\text { JS517 (peat soil, Loagan } \\
\text { Bunut) }\end{array}$ \\
\hline A. sulphureus ${ }^{*}$ & 0.05 & JS500 (peat soil, UNIMAS) \\
\hline A. niger & ND & JS024 (lake soil, Samarahan) \\
\hline A. niger & ND & $\begin{array}{l}\text { JS025 (citrus leaves, } \\
\text { Samarahan) }\end{array}$ \\
\hline A. niger & ND & $\begin{array}{l}\text { JS022 (peat soil, Loagan } \\
\text { Bunut) }\end{array}$ \\
\hline A. flavus & ND & $\begin{array}{l}\text { JS157 (dead wood, Bau } \\
\text { Limestone) }\end{array}$ \\
\hline A. flavus Link & ND & JS027 (peat soil, Samunsam) \\
\hline A. flavus & ND & JS026 (peat soil, UNIMAS) \\
\hline A. carbonarius ${ }^{*}$ & N.10 & JS742 (peat soil, Samarahan) \\
\hline A. carbonarius & ND & JS744 (peat soil, Bintulu) \\
\hline A. carbonarius & ND & JS752 (leaf litter, Bintulu) \\
\hline A. terreus & ND & JS910 (leaf litter, UNIMAS) \\
\hline A. terreus & ND & JS911 (peat soil, UNIMAS) \\
\hline A. terreus & ND & $\begin{array}{l}\text { JS912 (Riverine, Loagan } \\
\text { Bunut) }\end{array}$ \\
\hline A. fumigatus & ND & JS1006 (beach soil, Lundu) \\
\hline A. fumigatus & JS1001 (beach soil, Lundu) \\
\hline A. fumigatus & JS2003 (soil, Mukah) \\
\hline
\end{tabular}

* - Ochratoxin (OA) positive for ELISA's Test; ND - Not Detected

sulphureus were 0.05 to $0.10 \mu \mathrm{g} \mathrm{ml}^{-1}$, respectively (Table 1). The $O A$ concentration that was obtained in this study was lower in concentration compared to the standard $\mathrm{OA}$ found in $A$. ochraceus $\left(250 \mu \mathrm{g} \mathrm{ml}^{-1}\right)$. These two strains from our tropical region proved to be a low OA producer, similar to A. glaucus and the black Aspergillus strains (Abarca et al. 1994). OA production in A. carbonarius and $A$. sulphureus was confirmed by HPLC comparing the UV spectra as recorded with a diode array detector. The retention times (4.417 and 4.081) and UV spectra were similar to that of the OA standard (Figure 1).

\section{Conclusion}

The immunochemical method based on the application of a monoclonal antibody preparation against OA proved to be a useful tool for the screening of ochratoxin production among the Aspergilli. The present study helps to eliminate the toxic producing Aspergillus strains. It also showed that only minimum concentrations of ochratoxin producing Aspergillus occurred compared to the temperate region countries.

\section{References}

Abarca, M.L., F. Accensi, M.R. Bragulat, G. Castella \& F.J. Cabanes (2003). Aspergillus carbonarius as the main source of ochratoxin A contamination in dried wine fruits from the Spanish market. Journal of Food Protection 66: 504-506.

Abarca, M.L., M.R. Bragulat, G. Castella \& F.J. Cabanes (1994). Ochratoxin A production by strains of Aspergillus niger var. niger. Applied and Environmental Microbiology 60: 2650-2652.

Battaglia, R., T. Hatzold \& R. Kroes (1996). Conclusions from the workshop on ochratoxin in food. Food Additives and Contaminants 13: 1-3.

Ciegler, A. (1972). Biproduction of ochratoxin A and penicillic acid by members of the Aspergillus ochraceus group. Canadian Journal of Microbiology 18: 631-636.

Harwig, J. (1974). Ochratoxin A and related metabolites, pp. 345-367. In: Purchase, I.F.H. (ed.). Mycotoxins. Elsevier Scientific Publishing Company, Amsterdam, 702pp.

Hesseltine, C.W., D.I. Vandergraft, M.L. Fennell, Smith \& O.L. Shotwell (1972). Aspergilli as ochratoxin producers. Mycologia 64: 539-550.

Klich, M.A. (2002). Identification of Common Aspergillus Species. $1^{\text {st }}$ Edition. Centraalbureau voor Schimmelcultures, Utrecht, Netherlands, 122pp.

Raper, K.B. \& D.I. Fennell (1965). The Genus Aspergillus. Williams and Wilkins, Baltimore, 686pp.

Samson, R.A., E.S. Hoekstra \& J.C. Frisvad (2004). Introduction to Food and Airborne Fungi. $7^{\text {th }}$ Edition. Centraalbureau voor Schimmelcultures, Utrecht, Netherlands.

Scott, D.B. (1965). Toxigenic fungi isolated from cereal and legume products. Mycopathologia and Applied Mycology 25: 213-222.

Teren, J., J. Varga, Z. Hamari, E. Rinyu \& E. Kevei (1996). Immunochemical detection of ochratoxin A in black Aspergillus strains. Mycopathologia 134: 171-176.

Varga, J., E. Kevei, E. Rinyu, J. Teren \& Z. Kozakiewicz (1996). Ochratoxin production by Aspergillus species. Applied and Environmental Microbiology 62: 4461-4464.

Wang, J., Y. Huang, M. Fang, Y. Zhang, Z. Zheng, Y. Zhao \& W. Su (2002). Brefeldin A, a cytotoxin produced by Paecilomyces sp. and Aspergillus clavatus isolated from Taxus mairei and Torreya grandis. FEMS Immunology and Medical Microbiology 34: 51-57. 